\title{
Dehydrosulfurization of Aromatic Thioamides to Nitriles Using Indium(III) Triflate
}

\author{
Tomoko Mineno*, Yu Takebe, Chiaki Tanaka, Sho Mashimo \\ Laboratory of Medicinal Chemistry, Faculty of Pharmacy, Takasaki University of Health and Welfare, Takasaki, \\ Gunma, Japan \\ Email: ${ }^{*}$ mineno@takasaki-u.ac.jp
}

Received 20 June 2014; revised 5 August 2014; accepted 20 August 2014

Copyright $(2014$ by authors and Scientific Research Publishing Inc.

This work is licensed under the Creative Commons Attribution International License (CC BY). http://creativecommons.org/licenses/by/4.0/

(c) (i) Open Access

\section{Abstract}

The efficient dehydrosulfurization of thioamides to nitriles was carried out using indium(III) triflate as a catalyst. Based on the results of the initial study, the optimal reaction conditions required $5 \mathrm{~mol} \%$ of indium(III) triflate with toluene as the practical solvent. Various thioamides were successfully converted to nitriles in high yields.

\section{Keywords}

Indium(III) Triflate, Dehydrosulfurization, Thioamide, Nitriles

\section{Introduction}

Functional group conversions are of significant importance in the field of organic synthesis. Hence, the development of novel functional group conversions is a world-wide pursuit. Organosulfur compounds have been recognized as highlyuseful precursors, or synthons, in order to demonstrate functional grouptransformation [1]. Due to their considerable versatility and unique reactivity, thioamides are receiving increased attention, and many precedent interconverting reactions have been introduced. However, the dehydrosulfurization of thioamides to nitriles is often implemented under harsh reaction conditions that require elongated reaction times. Several studies that have focused on the dehydrosulfurization of thioamides to nitrileshave used reagents such as diphosphorus tetraiodide [2], 2, 4-dichloro-5-nitropyrimidine [3], and aryl chlorothionoformate [4] or a combination of reagents like $\mathrm{S}_{8} / \mathrm{NaNO}_{2} / \mathrm{NH}_{3}$ [5] and benzyl chloride/tetra- $n$-butylammonium bromide as a phase transfer catalyst [6]. In alternative conversions of thioamides to nitriles, researchers have employed metal reagents by intro-

*Corresponding author.

How to cite this paper: Mineno, T., Takebe, Y., Tanaka, C. and Mashimo, S. (2014) Dehydrosulfurization of Aromatic Thioamides to Nitriles Using Indium(III) Triflate. International Journal of Organic Chemistry, 4, 169-173.

http://dx.doi.org/10.4236/ijoc.2014.43018 
ducing reactions with silver carboxylates [7] [8], manganese oxide [9], and $n$-butyltin oxide [10]. Ogura et al. has reported for the dehydrosulfurization of thioamides to nitriles by using selenium-based and tellurium-based reagents [11]-[15], while Enthaler et al. has reported using iron-based and zinc-based reagents [16] [17]. We have studied the catalytic utility of indium reagents, and reported the chemical application of indium reagents, including an efficient conversion of primary amides to nitriles using catalytic indium(III) triflate [18]-[24]. In ongoing research, we have found that the catalytic use of indium(III) triflate facilitates the dehydrosulfurization of thioamides to nitriles. Herein, we describe the details of our study.

\section{Results and Discussion}

Using 3-methyl thiobenzamide as the starting substrate, a search for the optimal conditions of dehydrosulfurization was attempted, as presented in Table 1 . The amount of $N$-methyl- $N$-(trimethylsilyl)trifluoroacetamide (MSTFA) was fixed at 3.5 equivalents, as established in our previous report (Figure 1) [24], and thus the catalytic amount of indium(III) triflate and appropriate solvents were investigated. The entries using toluene as the solvent afforded the expected products (Table 1, entries 1 and 2), whereas the entries using THF ended with no reactions (Table 1, entries 3 and 4). The use of $5 \mathrm{~mol} \%$ of indium(III) triflate was also discovered as one of the key factors for the optimal reaction conditions (Table 1, entry 2).

Once the optimal conditions for the dehydrosulfurization of thioamides to nitriles were obtained, we next examined their applicability. Various aromatic thiobenzamides were subjected to dehydrosulfurization reactions. As shown in Table 2, the reactions proceeded smoothly to give the corresponding nitriles in good to excellent yields [24]. The alkyl group substituents,such as methyl on the aromatic ring and the tert-butyl groups were inert under the reaction conditions of dehydrosulfurization, and gave high yields (Table 2, entries 1, 3, and 5) [25] [26]. The dehydrosulfurization reactions of halogenated aromatic thioamides were carried out without dehalogenation (Table 2, entries 2 and 7) [27]. Also, the reaction led to the desired nitriles without damaging methoxy functionality (Table 2, entries 4 and 6). Consequently, the scope of the silyl protecting groups was investigated. The conversion reaction was successfully conducted maintaining both tert-butyldimethylsilyl (TBDMS) and tert-butyldiphenylsilyl (TBDPS) functionalities, and furnished the desired products in excellent order (Table 2, entries 8 and 9), which supported the mildness of the reaction conditions by not affecting the acid labile silyl functionalities. Furthermore, these reaction processes were extended to bicyclic aromatic compounds. The dehydrosulfurization reactions starting with naphthalene-1-thiocarboxamide and naphthalene-2-thiocarboxamide provided the corresponding nitriles in excellent yields (Table 2, entries 10 and 11). In addition, the entry using 2, 2-diphenylthioacetamide, which is a non-aromatic, afforded the desired nitrile productin an $84 \%$ yield (Table 2, entry 12) [28].

Table 1. Reactions in the search for optimal conditions.

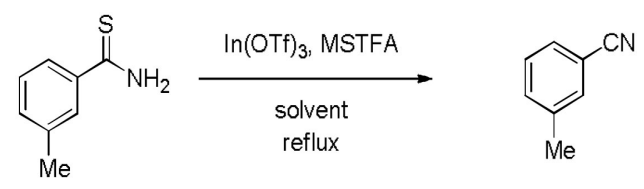

\begin{tabular}{cccccc}
\hline Entry & Solvent & MSTFA & In(OTf) & \multicolumn{2}{c}{ Reflux Time (h) $_{3}$} \\
\hline 1 & toluene & 3.5 eq. & 10 mol\% & 36 & 3 \\
2 & toluene & 3.5 eq. & 5 mol\% & 3 quant & N.R. \\
3 & THF & 3.5 eq. & 10 mol\% & 5 mol\% & 3 \\
4 & THF & 3.5 eq. & N.R. \\
\hline
\end{tabular}

${ }^{\mathrm{a}}$ Isolated yields.<smiles>CN(C)C(=O)C(F)(F)F</smiles>

MSTFA

Figure 1. Structure of $N$-methyl- $N$-(trimethylsilyl)trifluoroacetamide (MSTFA). 
Table 2. Dehydrosulfurization of aromatic thioamides to nitriles.

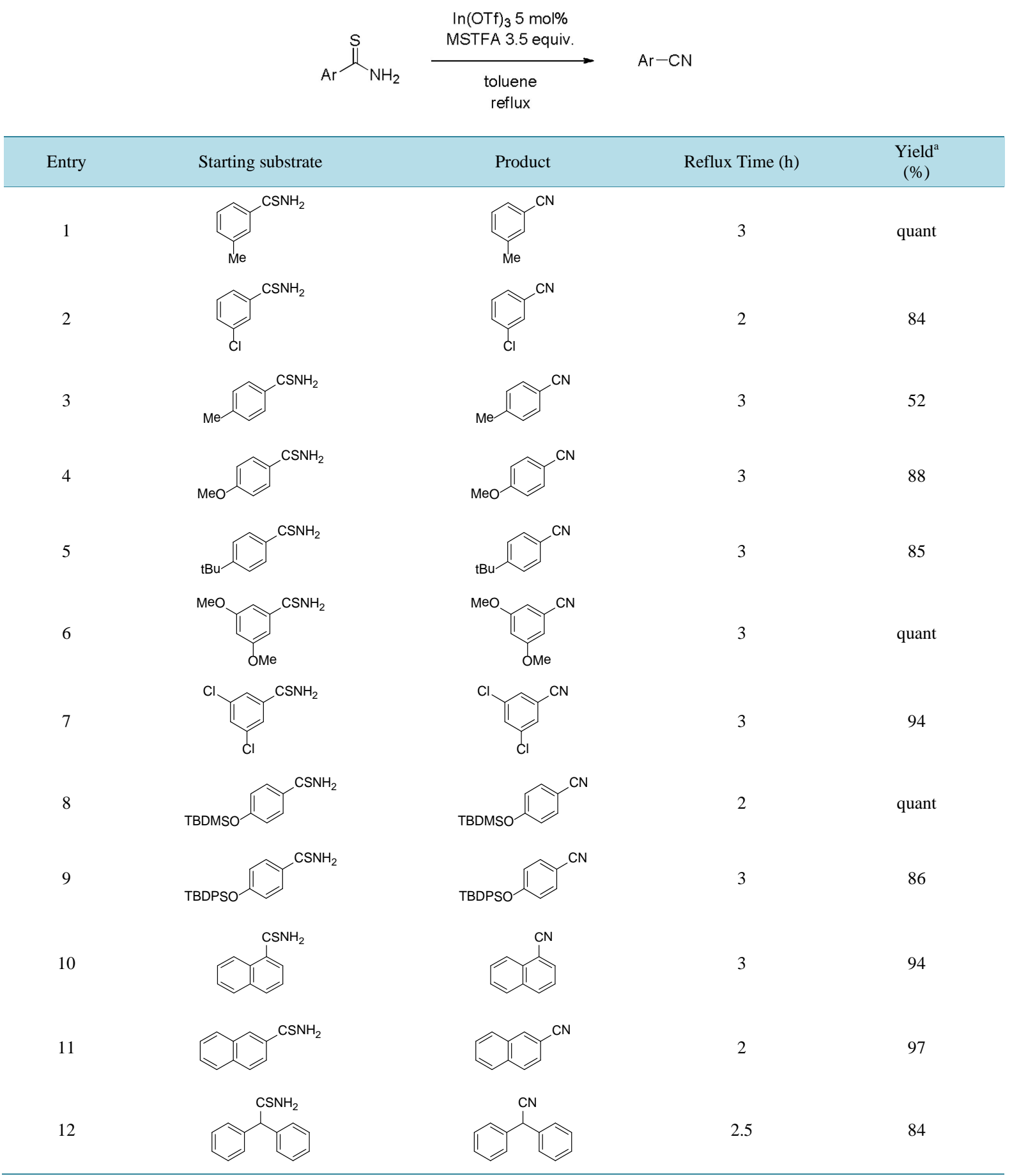

\section{Conclusion}

In conclusion, we have established an efficient method for the dehydrosulfurization of thioamides to nitriles in the presence of a catalytic amount of indium(III) triflate. Many aromatic thioamides were subjected to these reaction conditions, and provided the corresponding nitriles in good to excellent yields. The dehydrosulfurization reaction conditions were sufficiently mild, so as to not cleave the acid labile silyl functionalities. Further mechanistic investigations are ongoing. 


\section{Experimental}

\subsection{Materials and Instruments}

All reagents were of analytical grade and were purchased commercially and used without further purification. All reactions were carried out under an argon atmosphere using magnetic stirring unless otherwise noted. ${ }^{1} \mathrm{H}$ NMR and ${ }^{13} \mathrm{C}$ NMR spectral data were recorded on a JEOL JMTC-500 spectrometer using TMS as an internal standard.

\subsection{General Experimental Procedure}

The starting thioamide substrates $(1 \mathrm{mmol})$ and $\operatorname{In}(\mathrm{OTf})_{3}(5 \mathrm{~mol} \%)$ were dissolved in dehydrated toluene $(6 \mathrm{~mL})$ contained in a $100 \mathrm{~mL}$ flask equipped with a magnetic stirrer and a reflux condenser. MSTFA (3.5 mmol) was added using a syringe at room temperature. The reaction mixture was heated at reflux for $3 \mathrm{~h}$, and was monitored for completion by TLC. After the reaction mixture was cooled to room temperature, the solvent was washed with aqueous solutions and concentrated by rotary evaporation. Flash column chromatography on silica gel furnished the corresponding nitrile product, which was confirmed by spectroscopy [24]-[28].

\section{References}

[1] Satchell, D.P.N. (1977) Metal-Ion-Promoted Reactions of Organo-Sulphur Compounds. Chemical Society Reviews, 6, 345-371. http://dx.doi.org/10.1039/CS9770600345

[2] Suzuki, H., Tani, H. and Takeuchi, S. (1985) Desulfurization of Thioketones and Thioamides with Diphosphorus Tetraiodide. Bulletin of the Chemical Society of Japan, 58, 2421-2422. http://dx.doi.org/10.1246/bcsj.58.2421

[3] Kondo, K., Komamura, C., Murakami, M. and Takemoto, K. (1985) 2,4-Dichloro-5-nitropyrimidine as a New Dehydrating or Desulfhydrating Reagent. Synthetic Communications, 15, 171-177. http://dx.doi.org/10.1080/00397918508063784

[4] Bose, D.S. and Goud, P.R. (1999) Aryl Chlorothionoformate: A New Versatile Reagent for the Preparation of Nitriles and Isonitriles under Mild Conditions. Tetrahedron Letters, 40, 747-748. http://dx.doi.org/10.1016/S0040-4039(98)02361-2

[5] Sato, R., Itoh, K., Itoh, K., Nishina, H., Goto, T. and Saito, M. (1984) Novel Conversion of Aromatic Thioamides and Aldehydes into Nitriles with Elemental Sulfur and Sodium Nitrite in Liquid Ammonia. Chemistry Letters, 11, 19131916. http://dx.doi.org/10.1246/cl.1984.1913

[6] Funakoshi, Y., Takido, T. and Itabashi, K. (1985) Facile Conversion of Primary Thioamides into Nitriles with Benzyl Chloride under Phase Transfer Conditions. Synthetic Communications, 15, 1299-1303. http://dx.doi.org/10.1080/00397918508077278

[7] Avalos, M., Babiano, R., Duran, C.J., Jimenez, J.L. and Palacios, J.C. (1994) Reaction of Thioamides with Silver Carboxylates in Aprotic Media. A Nucleophilic Approach to the Synthesis of Imides, Amides, and Nitriles. Tetrahedron Letters, 35, 477-480. http://dx.doi.org/10.1016/0040-4039(94)85085-2

[8] Avalos, M., Babiano, R., Cintas, P., Duran, C.J., Higes, F.J., Jimenez, J.L., Lopez, I. and Palacios, J.C. (1997) Reaction of Thioamides with Metal Carboxylates in Organic Media. Tetrahedron, 53, 14463-14480. http://dx.doi.org/10.1016/S0040-4020(97)00938-1

[9] Yamaguchi, K., Yajima, K. and Mizuno, N. (2012) Facile Synthesis of Nitriles via Manganese Oxide Promoted Oxidative Dehydrosulfurization of Primary Thioamides. Chemical Communications, 48, 11247-11249. http://dx.doi.org/10.1039/c2cc36635e

[10] Lim, M.-I., Ren, W.-Y. and Klein, R.S. (1982) Facile Conversion of Primary Thioamides into Nitriles with Butyltin Oxides. Journal of Organic Chemistry, 47, 4594-4595. http://dx.doi.org/10.1021/jo00144a043

[11] Hu, N.X., Aso, Y., Otsubo, T. and Ogura, F. (1985) Mild and Selective Oxidations with Polystyrene-Bound Diaryl Selenoxide. Chemistry Letters, 14, 603-606. http://dx.doi.org/10.1246/cl.1985.603

[12] Hu, N.X., Aso, Y., Otsubo, T. and Ogura, F. (1986) Polymer-Supported Diaryl Selenoxide and Telluroxide as Mild and Selective Oxidizing Agents. Bulletin of the Chemical Society of Japan, 59, 879-884. http://dx.doi.org/10.1246/bcsj.59.879

[13] Hu, N.X., Aso, Y., Otsubo, T. and Ogura, F. (1986) Novel Oxidizing Properties of p-Methoxybenzenetellurinic Acid Anhydride. Tetrahedron Letters, 27, 6099-6102. http://dx.doi.org/10.1016/S0040-4039(00)85408-8

[14] Fukumoto, T., Matsuki, T., Hu, N.X., Aso, Y., Otsubo, T. and Ogura, F. (1990) Benzenetellurinic Mixed Anhydrides as Mild Oxidizing Agents. Chemistry Letters, 19, 2269-2272. http://dx.doi.org/10.1246/cl.1990.2269 
[15] Aso, Y., Omote, K., Takagi, S., Otsubo, T. and Ogura, F. (1995) Mild and Efficient Dehydrosulfurization of Thioamides to Nitriles Induced by Tellurium or Selenium Tetrachloride with Triethylamine. Journal of Chemical Research, Synopses, No. 4, 152-153.

[16] Enthaler, S. (2011) Straightforward Iron-Catalyzed Synthesis of Nitriles by Dehydration of Primary Amides. European Journal of Organic Chemistry, 2011, 4760-4763. http://dx.doi.org/10.1002/ejoc.201100754

[17] Enthaler, S. and Inoue, S. (2012) An Efficient Zinc-Catalyzed Dehydration of Primary Amides to Nitriles. Chemistry—An Asian Journal, 7, 169-175. http://dx.doi.org/10.1002/asia.201100493

[18] Mineno, T. (2002) A Fast and Practical Approach to Tetrahydropyranylation and Depyranylation of Alcohols Using Indium Triflate. Tetrahedron Letters, 43, 7975-7978. http://dx.doi.org/10.1016/S0040-4039(02)01864-6

[19] Mineno, T. and Kansui, H. (2006) High Yielding Methyl Esterification Catalyzed by Indium(III) Chloride. Chemical \& Pharmaceutical Bulletin, 54, 918-919. http://dx.doi.org/10.1248/cpb.54.918

[20] Mineno, T., Nikaido, N. and Kansui, H. (2009) One-Step Transformation of Tetrahydropyranyl Ethers Using Indium(III) Triflate as the Catalyst. Chemical \& Pharmaceutical Bulletin, 57, 1167-1170. http://dx.doi.org/10.1248/cpb.57.1167

[21] Mineno, T., Sakai, M., Ubukata, A., Nakahara, K., Yoshimitsu, H. and Kansui, H. (2013) The Effect of Indium(III) Triflate in Oxone-Mediated Oxidative Methyl Esterification of Aldehydes. Chemical \& Pharmaceutical Bulletin, 61, 870-872. http://dx.doi.org/10.1248/cpb.c13-00072

[22] Mineno, T., Tsukagoshi, R., Iijima, T., Watanabe, K., Miyashita, H. and Yoshimitsu, H. (2014) Reductive Coupling Reaction of Aldehydes Using Indium(III) Triflate as the Catalyst. Tetrahedron Letters, 55, 3765-3767. http://dx.doi.org/10.1016/j.tetlet.2014.05.079

[23] Mineno, T., Yoshino, S. and Ubukata, A. (2014) Oxone-Mediated Oxidative Esterification of Heterocyclic Aldehydes Using Indium(III) Triflate. Green and Sustainable Chemistry, 4, 20-23. http://dx.doi.org/10.4236/gsc.2014.41004

[24] Mineno, T., Shinada, M., Watanabe, K., Yoshimitsu, H., Miyashita, H. and Kansui, H. (2014) Highly-Efficient Conversion of Primary Amides to Nitriles Using Indium(III) Triflate as the Catalyst. International Journal of Organic Chemistry, 4, 1-6. http://dx.doi.org/10.4236/ijoc.2014.41001

[25] Littke, A., Soumeillant, M., Kaltenbach III, R.F., Cherney, R.J., Tarby, C.M. and Kiau, S. (2007) Mild and General Methods for the Palladium-Catalyzed Cyanation of Aryl and Heteroaryl Chlorides. Organic Letters, 9, 1711-1714. http://dx.doi.org/10.1021/ol070372d

[26] Grossman, O. and Gelman, D. (2006) Novel Trans-Spanned Palladium Complexes as Efficient Catalysts in Mild and Amine-Free Cyanation of Aryl Bromides under Air. Organic Letters, 8, 1189-1191. http://dx.doi.org/10.1021/ol0601038

[27] Yang, C. and Williams, J.M. (2004) Palladium-Catalyzed Cyanation of Aryl Bromides Promoted by Low-Level Organotin Compounds. Organic Letters, 6, 2837-2840. http://dx.doi.org/10.1021/ol049621d

[28] Katritzky, A.R., Akue-Gedu, R. and Vakulenko, A.V. (2007) C-Cyanation with 1-cyanobenzotriazole. ARKIVOC, 2007, 5-12. http://dx.doi.org/10.3998/ark.5550190.0008.302 
Scientific Research Publishing (SCIRP) is one of the largest Open Access journal publishers. It is currently publishing more than 200 open access, online, peer-reviewed journals covering a wide range of academic disciplines. SCIRP serves the worldwide academic communities and contributes to the progress and application of science with its publication.

Other selected journals from SCIRP are listed as below. Submit your manuscript to us via either submit@scirp.org or Online Submission Portal.
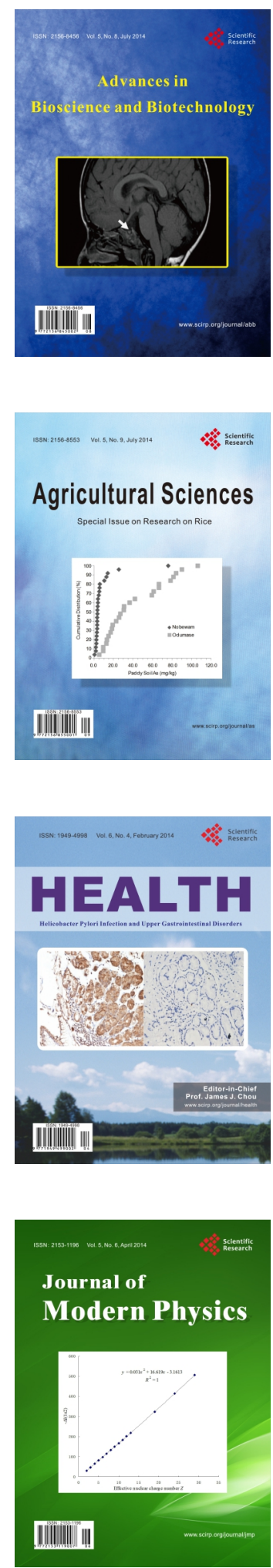
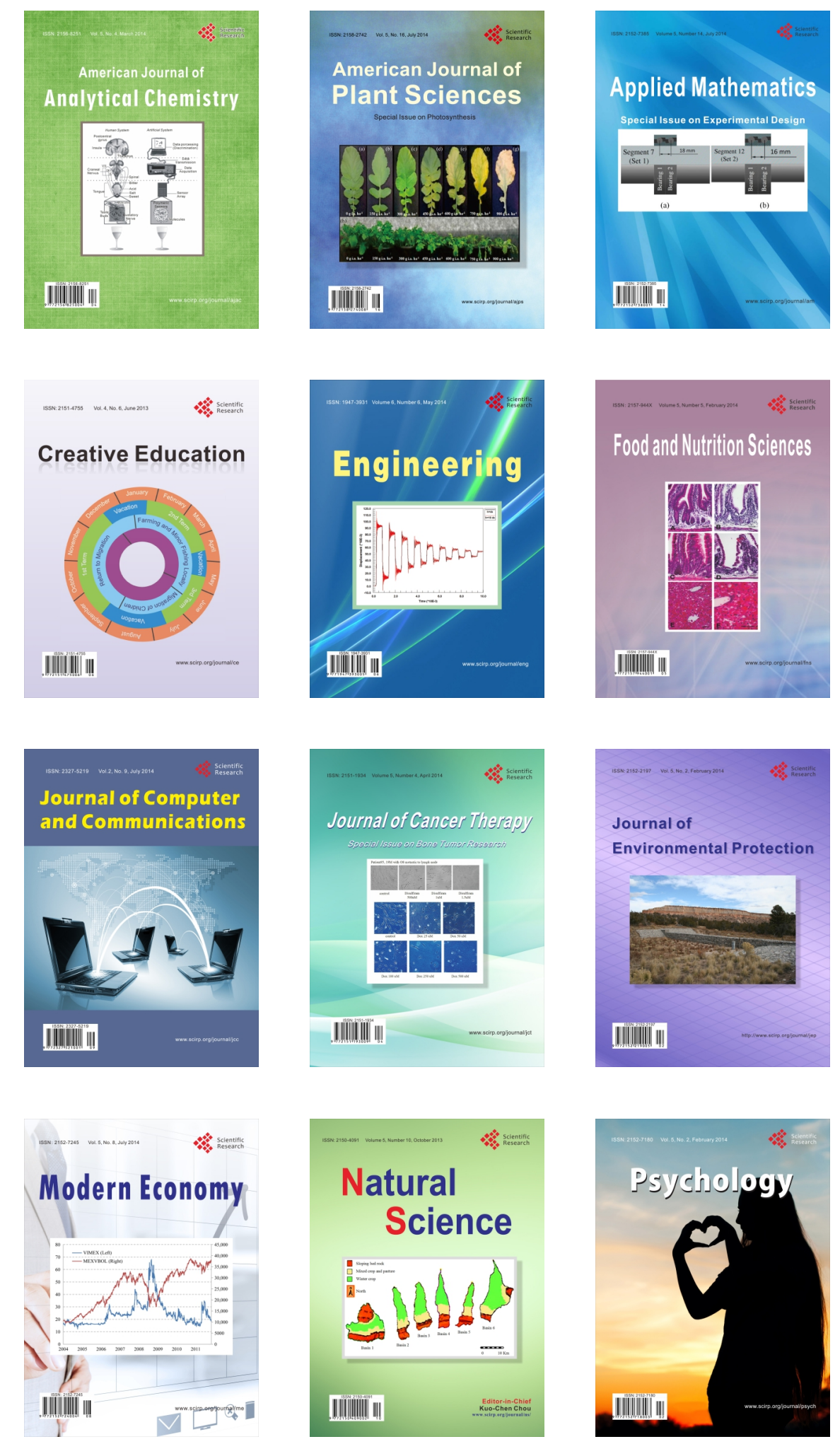